\title{
HIGHLIGHTS OF 30 YEARS OF STRONG-MOTION RECORDING IN NEW ZEALAND
}

\author{
W.J. Cousins
}

\begin{abstract}
Strong-motion recording has been carried out in New Zealand for somewhat more than 30 years. The largest network of instruments, comprising 220 accelerographs and 72 scratch-plate acceleroscopes, is operated by the Institute of Geological and Nuclear Sciences.

During the last 30 years the IGNS network has yielded a little over 2000 records, 1600 of which have been matched with earthquake events to give a substantial body of New Zealand data that is currently being used in studies of attenuation and microzonation. The highest peak ground accelerations recorded to date on scratch-plates and accelerographs are respectively $0.6 \mathrm{~g}$ (from Reefton during the 1968 Inangahua earthquake) and $0.4 \mathrm{~g}$ (from Dannevirke from the Weber earthquake of 13th May 1990).
\end{abstract}

About 300 of the more significant accelerograms have been digitized and computer processed to give data sets suitable for use in aseismic structural design, and studies of the attenuation of spectral acceleration, soil-structure interactions, structural responses, and microzonation.

Peak ground accelerations from New Zealand earthquakes appear to be stronger, over a wide range of source distances, than predicted from attenuation models applicable to the Western USA. Spectral accelerations in New Zealand appear to modelled well by a model based on Japanese data, but some caution is needed as the New Zealand data base of spectral accelerations is small and deficient in near source data from moderate to large earthquakes.

Strong-motion records from deep or soft soil sites, and from arrays of recorders in the Wellington region, have shown both resonant and broad-band amplification for rock input motions of small to moderate intensity.

Sets of records from arrays of accelerographs in three medium-rise buildings have revealed the effects of soil-structure interactions, and records from an array of 5 accelerographs on Matahina dam showed that part of the dam responded in a strongly nonlinear fashion during the 1987 Edgecumbe earthquake.

\section{INTRODUCTION}

Engineering Seismology Section of the Institute of Geological and Nuclear Sciences (IGNS) (formerly the Physics and Engineering Laboratory, DSIR) began operating a network of strong-motion earthquake recorders in New Zealand in the 1960 's. By 1970 the network had grown to 151 recorders, of which 77 were film-recording accelerographs and 74 were scratch-plate acceleroscopes [20]. By 1980 the number of accelerographs had increased to about 150 [19], and currently, 1993, there are 220 accelerographs distributed over 137 sites (Fig. 1). Somewhat more than half of the accelerographs, 111, are located in structural arrays in buildings (19 sites), bridges (4 sites), dams ( 8 sites), power stations ( 2 sites), and an offshore gas platform (1 site). The remainder, 109, are in either free-field sites or as single

Institute of Geological and Nuclear Sciences, Lower Hutt (Member) instruments on the ground floor of a building. Forty of the accelerographs are backed up with acceleroscopes, and a further 32 ground sites are monitored with acceleroscopes alone.

The Civil Engineering Department of Canterbury University also operates some film-recording accelerographs in the northern part of the South Island (Fig. 1). Together the two networks of accelerographs ensure that there will be at least one accelerograph within $50 \mathrm{~km}$ of any epicentre located on land throughout nearly all of the two main seismic regions of New Zealand (Inset, Fig. 1), and therefore come very close to meeting the minimal coverage level recommended by Berrill in 1979 [3].

The purpose of the networks is to measure the responses of various kinds of structures and soils to strong ground shaking caused by moderate-to-large earthquakes in New Zealand. The results, together with selected data from major overseas 


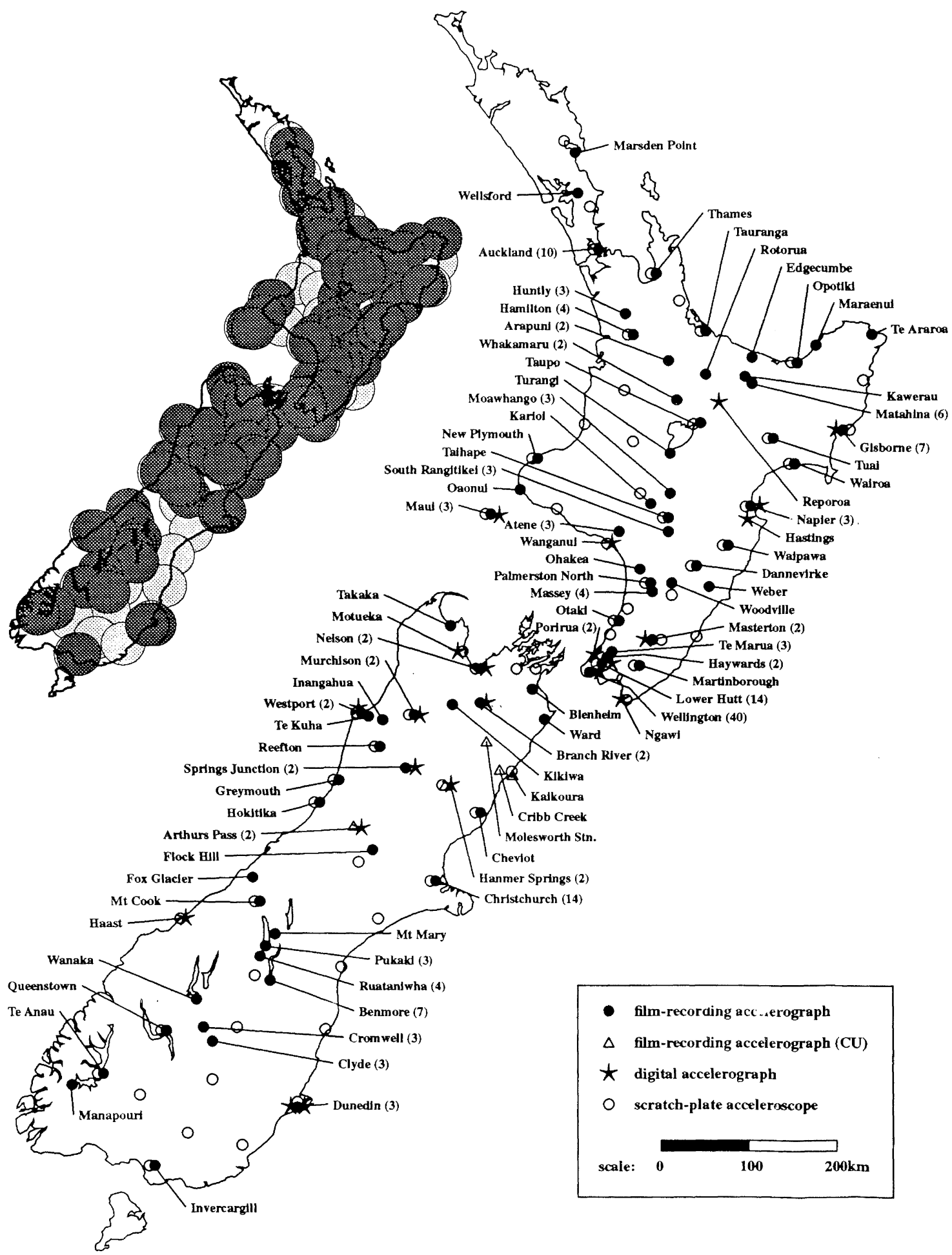

Figure 1. Recording sites in the New Zealand strong-motion network as at the 1st of March 1993. The numbers in brackets after the site names are numbers of accelerographs, and "CU" indicates instrument operated by Canterbury University. The inset shows the regions within $50 \mathrm{~km}$ of accelerographs (dark shading) or acceleroscopes (light shading). 
earthquakes, are used (a) to predict the strength of shaking in future earthquakes, (b) in studies of microzonation, (c) to test existing methods of earthquake-resistant design, (d) to guide the development of products and processes, including seismic isolation, that improve the safety and repairability of all types of construction, and (e) to estimate possible economic losses caused by earthquakes.

Decisions on the siting of accelerographs have had to take all of the above into account. A primary aim has been to achieve at least a low density coverage of the two main seismic region, ie near Fiordland and along a broad line from Westport to East Cape, and to cover as much of the remainder of New Zealand as possible, with acceleroscopes filling in any gaps. The intention is to fill the remaining gaps with accelerographs over next year or two.

During recent years increased emphasis has been given to placing further accelerographs within a few kilometres of several of the major active faults with the aim of capturing near-fault motions arising from major events. The existing microzone array in the Wellington-Hutt Valley area has been strengthened and minimal microzone installations, with at least rock and soil site pairs, have been established in Gisborne, Napier, and Hastings.

Arrays of accelerographs on structures of interest continue to hold high priority with the aim of measuring the performances of (a) buildings designed to code(s), (b) special structures such as base isolated buildings and bridges, and (c) major dams. Many of the instruments on structures are funded by potential users of any data, for example, the Electricity Corporation of New Zealand.

To date the IGNS network has produced more than 2000 records. Nearly $60 \%$ of the records have been matched definitely with earthquake events, and possible events have been found for a further $20 \%$. Approximately 300 of the records have been computer processed to yield time histories and spectra in formats suitable for use in earthquake-resistant design and seismic hazard studies. The results of the computer processing for the most significant records have been published as data reports [2,6-11] which, along with time history and response spectral data files, are available from the Institute at nominal cost. The most recent data report [12] lists the peak accelerations for all of the records and, where known, gives source locations and magnitudes and epicentral distances.

The first major records from the network were generated by the Inangahua earthquake of 1968 . All were from acceleroscopes, because even though there was an early model of accelerograph at Westport it was inoperative at the time of the mainshock because of battery failure. The five largest peak ground accelerations (PGA's) recorded are listed in Table 1.

Since the Inangahua earthquake many significant records, including some large sets, have been obtained from both accelerographs and acceleroscopes, but $0.61 \mathrm{~g}$ remains the largest PGA recorded by the New Zealand network (Tables 2 and 3$)$.

The strong-motion network has changed significantly since it was last described in the Bulletin 10 years ago. The purpose of the present report is to update the earlier papers [19-21] and to present some highlights of the research based on the strong-motion records.
Table 1. Largest strong-motion records from the 1968 Inangahua earthquake $[12,17]$

\begin{tabular}{|c|c|c||}
\hline Site name & $\begin{array}{c}\text { PGA } \\
(\mathrm{g})\end{array}$ & $\begin{array}{c}\text { Epicentral } \\
\text { distance } \\
(\mathrm{km})\end{array}$ \\
\hline \hline Reefton & 0.61 & 41 \\
\hline Greymouth & 0.40 & 101 \\
\hline Murchison & 0.37 & 23 \\
\hline Westport & 0.34 & 36 \\
\hline Hokitika & 0.19 & 138 \\
\hline
\end{tabular}

\section{THE NEW ZEALAND NETWORK}

\section{Instrumentation}

The primary instrument of the New Zealand network is the locally manufactured $\mathrm{MO}$ (mechanical-optical)accelerograph. It records accelerations in three orthogonal directions as traces on unperforated $35 \mathrm{~mm}$ film [21]. Accelerations are measured with damped pendulums which deflect light beams in proportion to the accelerations. $50 \mathrm{~Hz}$ timing marks are recorded directly on the film, and the most recent version of the instrument also imprints a time code at the end of each recording. The accelerograph is normally in stand-by mode and is switched on by a vertically-sensing geophone when the acceleration reaches approximately $0.01 \mathrm{~g}$. It contains sufficient film for approximately 6 minutes of recording, equivalent to 8 to 10 moderate earthquakes.

Over recent years 47 digital accelerographs have been installed in the New Zealand network. They are Terra Technology type DCA-333R instruments, which record the digital data in solid state memory for later retrieval by portable computer. Significant specifications of the recorders are

- accelerometers, triaxial servo, $0.001 \mathrm{~g}$ resolution, $2 \mathrm{~g}$ full scale;

- sampling interval, 0.01 second;

- pre-event memory, 4 seconds;

- real time internal clock;

- trigger level, usually $0.005 \mathrm{~g}$; and

- memory capacity, 10 minutes.

Many of the accelerographs are backed up with two-component SP (scratch plate) acceleroscopes which give a measure of the amplitude and direction of the principal acceleration in the horizontal plane. Acceleration is sensed with a damped pendulum and is recorded as a line scribed in a thin layer of smoke-blackened wax that is supported on a glass disk of $13 \mathrm{~mm}$ diameter. The scriber is a specially sharpened sewing needle.

\section{Maintenance and Calibration}

All of the strong-motion instruments are serviced 8 monthly apart from (a) two located on the Maui Offshore Platform which are visited 4 monthly because of the hostile conditions prevailing at the site, and (b) digital accelerographs at some sites of special interest. In-field service consists of replacing films and batteries, general maintenance, and minor repairs. 
Table 2. Numbers of strong-motion records from the New Zealand network.

\begin{tabular}{|c|c|c|c|}
\hline PGA & $\begin{array}{c}\text { Film } \\
\text { Recording } \\
\text { Accelerograph }\end{array}$ & $\begin{array}{c}\text { Digital } \\
\text { Accelerograph }\end{array}$ & $\begin{array}{c}\text { Scratch-Plate } \\
\text { Acceleroscope }\end{array}$ \\
\hline \hline $0.05-0.1$ & 181 & 12 & 139 \\
\hline $0.1-0.2$ & 54 & 2 & 54 \\
\hline $0.2-0.3$ & 11 & 0 & 10 \\
\hline$>0.3$ & 6 & 0 & 8 \\
\hline
\end{tabular}

Table 3. List of larger earthquakes that have yielded significant sets of records from the New Zealand strong-motion network [12].

\begin{tabular}{|c|c|c|c|c|c|c|}
\hline $\begin{array}{l}\text { Event } \\
\text { Date }\end{array}$ & $\begin{array}{c}\text { Local } \\
\text { Magnit- } \\
\text { ude } \\
\mathrm{M}_{\mathrm{L}}^{(1)} \\
\end{array}$ & $\begin{array}{l}\text { Hypo- } \\
\text { central } \\
\text { Depth } \\
(\mathrm{km})^{(1)} \\
\end{array}$ & $\begin{array}{l}\text { "Event Name," } \\
\text { or location }\end{array}$ & $\begin{array}{l}\text { Number } \\
\text { of } \\
\text { records }\end{array}$ & $\begin{array}{c}\text { Shortest } \\
\text { Epicentral } \\
\text { Distance } \\
(\mathrm{km})\end{array}$ & PGA \\
\hline $23 / 05 / 68$ & 6.7 & $12 \mathrm{R}^{(2)}$ & Inangahua $[41]^{(3)}$ & 12 & 23 & 0.61 \\
\hline $5 / 01 / 73$ & 7.0 & 173 & Central North Island & 51 & 65 & 0.16 \\
\hline $4 / 05 / 76$ & 6.5 & $12 \mathrm{R}$ & Milford Sound [21] & 7 & 43 & 0.10 \\
\hline $18 / 01 / 77$ & 6.0 & $33 \mathrm{R}$ & Cook Strait & 44 & 63 & 0.11 \\
\hline $8 / 03 / 84$ & 6.4 & 75 & Motu River [31] & 11 & 38 & 0.16 \\
\hline $2 / 03 / 87$ & 6.1 & $10 \mathrm{R}$ & Edgecumbe [42] & 10 & 25 & 0.34 \\
\hline $3 / 06 / 88$ & 5.7 & $73 R$ & Te Anau [32] & 15 & 47 & 0.18 \\
\hline $31 / 05 / 89$ & 6.1 & $23 R$ & Doubtful Sound & 6 & 41 & 0.11 \\
\hline $8 / 08 / 89$ & 6.0 & 122 & Offshore Patea & 52 & 58 & 0.10 \\
\hline $10 / 02 / 90$ & 5.8 & 13 & Lake Tennyson & 7 & 34 & 0.14 \\
\hline $19 / 02 / 90$ & 6.1 & 24 & Weber 1 [33] & 35 & 28 & 0.35 \\
\hline $13 / 05 / 90$ & 6.2 & 12 & Weber $2[33]$ & 40 & 19 & 0.40 \\
\hline $28 / 01 / 91$ & 6.1 & 8 & Hawks Crag 1 & 8 & 9 & 0.21 \\
\hline $28 / 01 / 91$ & 6.2 & 13 & Hawks Crag 2 & 21 & 8 & 0.33 \\
\hline $8 / 09 / 91$ & 6.3 & 87 & Offshore, Bulls & 60 & 20 & 0.16 \\
\hline $27 / 05 / 92$ & 6.4 & 84 & Offshore, Blenheim & 53 & 28 & 0.10 \\
\hline
\end{tabular}

Notes: 1. Magnitudes and depths were derived from an earthquake catalogue maintained by the New Zealand Seismological Observatory [35].

2. "R" indicates that the depth is poorly constrained and that a nominal value has been used.

3. Further information on the earthquakes is contained in the listed references.

Instruments are returned to the laboratory either if major work is necessary or for upgrading [19].

All instruments are calibrated statically before being placed in the field. Accelerometer blocks from the film-recording accelerographs are calibrated in a modified accelerograph body mounted on a universal table that allows the accelerometer block to be tilted successively to each of 8 specified orientations in the gravity field [34]. Each sensor of the block is thereby subjected to static accelerations of $0 \mathrm{~g}$, $\pm 0.577 \mathrm{~g}$, and $\pm 1.0 \mathrm{~g}$. Static sensitivities, corrections for cross-axis effects, and corrections for errors in the sensing axis directions are derived from the static measurements.

All of the digital accelerographs are calibrated under static conditions by the manufacturer using test equipment that is 
traceable to NBS standards (A Croft, Terra Technology Corp., personal communication 1993). One digital accelerograph has been formally calibrated at IGNS under static and dynamic conditions [1].

The scratch-plate acceleroscopes are calibrated statically by being mounted on a precision dividing head and tilted away from an initially level condition so as to give gravity forces of $0.1 \mathrm{~g}$ to $0.6 \mathrm{~g}$. One also has been calibrated dynamically over a limited range of accelerations [30].

Uncertainties in acceleration data from the various instruments are as follows. Approximate overall uncertainties in acceleration values derived from film accelerograms are $\pm 1 \%$, with an additional $\pm 0.003 \mathrm{~g}$ digitizer resolution, for fully processed records, and $\pm 6 \%$ and $\pm 0.003 \mathrm{~g}$ for partially processed records (see Section 4.2 below). The uncertainty in acceleration readings from the digital recorders is $\pm 1 \%$, and is due mainly to uncertainy in the sensitivity of the accelerometer. The resolution of the $\mathrm{A} / \mathrm{D}$ convertor is $\pm 0.001 \mathrm{~g}$. Finally, the uncertainty in peak acceleration values from scratch-plate records may vary typically between $\pm 5 \%$ and $\pm 20 \%$ of the value depending on factors such as clarity and amplitude of the recorded trace. The largest contribution to uncertainty is the location of the rest position of the stylus. This information is frequently lost because the central portion of the record disk may have been scraped clean by small amplitude motions and superimposed events between installation and retrieval of the scratch plate.

\section{Site geotechnical data}

The soil conditions beneath a site often have a large influence on the intensity of shaking at the site. During 1990 , as a project funded by the EQC (Earthquake and War Damage Commission), brief geotechnical descriptions were obtained for those sites in the network that had yielded strong-motion records of engineering significance. Work currently in progress has the aim of providing similar descriptions for recently instrumented sites and older low priority sites not covered previously.

\section{ACCELEROGRAM PROCESSING}

\section{Film accelerograms - full processing}

All films recovered from the MO instruments are developed and inspected as part of the instrument maintenance program. Those containing records of interest are contact copied, the copy being used in further processing and the original being stored securely. During the copying the film is overlain with a set of reference marks at $50 \mathrm{~mm}$ intervals giving approximately 3 seconds of data between each pair of marks. Segment enlargements are then made in the form of positive prints at 4-times magnification with the reference marks at the four corners.

Digitization of the segment enlargements is largely automated. An optical reflectance sensor attached to the pen carriage of a Tektronix 4662 plotter scans each print trace, the timemarks, and the reference points, while under computer control. The reflectance sensor detects the black trace line and the position of the pen carriage gives the coordinates of the digitised point. Readings are taken at approximate 10 millisecond record intervals [23]. Prints that are unsuitable for the automated system are digitized by hand on a Hewlett-Packard model 9874 A digitizer.
Data from each print is plotted, corrected if necessary, and then data from all prints is joined to give a complete three component uncorrected accelerogram. Header information on site and event locations and instrument characteristics is then added to give the Volume 1 file.

Until recently the digitization and Volume 1 processing has been based on a DEC LSI-11 workstation. They are now being transferred to an IBM compatible PC, and the plotter-based digitizer will be replaced as soon as possible with a scanner system.

Routine computer processing follows. It consists of correction for the dynamic frequency response of the accelerometer pendulums, band-pass filtering, and integration, and results in the computation of corrected acceleration, velocity, and displacement time histories. All phases are implemented in the frequency domain [23].

The purpose of the band-pass filtering is to minimise errors arising from aliasing and low frequency noise signals. The low-pass cutoff frequency is $25 \mathrm{~Hz}$ and the high-pass cutoff frequency, which is selected by inspection for each record [6], is generally near $0.3 \mathrm{~Hz}$.

The noise baseline for the film processing system was obtained by digitizing and processing straight-line records of 15 to 60 seconds length. Fourier spectra calculated from the straight-line data had a characteristic, approximately bilinear, envelope, with a maximum near $0.3 \mathrm{~Hz}$ that was primarily caused by interaction between the segment length of about 3 seconds and the $0.1 \mathrm{~mm}$ digitizer resolution. Printing distortions such as pincushion and tapering were small enough to be of secondary importance.

The noise baseline for the DCA-333R records is still being determined at the time of writing. "Records" obtained (a) by electrically triggering a recorder in the absence of signal input, and (b) with a sinusoidal input of $0.2 \mathrm{~g}$ at $7 \mathrm{~Hz}$ have indicated that a horizontal straight line at $0.002-0.004 \mathrm{~m} / \mathrm{s}$ in the Fourier amplitude spectrum is adequate for most of the digital records. In a few cases a low amplitude low frequency sawtooth type pattern apparently introduced by the removal of the trace mean as a baseline produces spurious low-frequency components.

Next, the absolute acceleration response spectrum is calculated from the peak responses of linear single-degree-of-freedom oscillators to the ground excitation [23]. Relative velocity and dislacement spectra also are calculated in a similar inan , $r$, and a Fourier amplitude spectrum is calculated from the mechanical energy per unit mass of an undamped linear oscillator at the end of the acceleration. The "mechanical energy" procedure for calculating the Fourier spectrum is used at this stage in preference to an FFT (Fast Fourier Transform) algorithm because the values are obtained at the same frequencies as the response spectral quantities which is convenient for tabular presentation. Fourier spectra of acceleration are also derived from an FFT algorithm for plotted results.

\section{Film accelerograms - partial processing}

Partial processing consists of measuring the peak accelerations for each signal trace on the original accelerogram films. Each film is inserted in a film reader that is also used for calibration of the accelerometers, and the distances between the reference trace and peaks in the 
signal traces are measured. The heights of the acceleration peaks are then calculated by subtracting the distances to the rest positions of the traces, and converted to accelerations using the static sensitivity values for the accelerometer. No corrections are made for errors in sensing-axis direction and cross-axis effects.

\section{Digital accelerograms}

Digital records from the DCA-333R instruments are processed in much the same way as the digitized film accelerograms with the exception that corrections for cross-axis effects and individual instrument characteristics are not required.

\section{Scratch-plate acceleroscope records}

All record disks are photographed using a purpose-built camera system that gives a negative image at $\mathrm{x} 10$ magnification. Significant records are printed at a further $\mathrm{x} 10$ magnification with scale markings superimposed on each print. The highest acceleration peak, and the resolved peaks in the North-South and East-West directions, are measured directly from each print, or from each negative film for minor records that have not been printed. The readings are converted to accelerations using the static sensitivity values for the accelerometers.

\section{Availability of printed and digital data}

Printed data reports are produced approximately annually [2,6-12]. They contain plots of the corrected earthquake motions, Fourier amplitude spectra, and acceleration response spectra, and tabulated values of the acceleration, velocity, and displacement response spectra and the Fourier amplitude spectra of the accelerations.

Corrected acceleration, velocity, and displacement time-history records, and the corresponding response spectral files are obtainable from IGNS, at nominal charge, ori a variety of magnetic media.

\section{SOME HIGHLIGHTS OF THE STRONG-MOTION RECORDS}

\section{Attenuation of PGA and spectral acceleration}

The collection of strong-motion data from New Zealand earthquakes is now sufficiently large to be useful in studies of attenuation. Particularly valuable for the derivation of models of PGA attenuation are the several sets of data referred to in Table 3, some of which have been used already in a preliminary study [16] which showed that a Japanese (Fukushima and Tanaka [18]) attenuation model provided a better fit to the New Zealand data than did models based on data from the Western USA and Europe. Importantly, both this study, and a special study of attenuation in the 1968 Inangahua earthquake [17], showed that peak ground accelerations from New Zealand earthquakes were usually stronger over a wide range of source distances than those obtained from attenuation models applicable to the Western USA.

The entire PGA data set of ground accelerograms, scaled with the aid of the Fukushima and Tanaka attenuation relation, is summarised in Figure 2. It shows the large spread typical of raw strong-motion data, and clearly there is scope for investigation of topics such as site amplification and resonance.

The modelling of the attenuation of spectral acceleration in New Zealand also is at an early stage, and the need to use fully processed records means that the data base is much smaller than that available for PGA modelling. In the early 1980's Mulholland [29] and McVerry [26] showed that acceleration response spectra calculated from the New Zealand accelerograms were modelled well by a modified form of the Katayama attenuation model. More recently, Matuschka and Davis [24] attempted to develop an attenuation model based soley on the New Zealand data, and although finding that their model differed in some respects from the commonly used overseas models, recommended against sole reliance on their model for the estimation of spectral acceleration because of the small size of the New Zealand data base

Work on the modelling of both PGA and spectral acceleration attenuation is continuing.

\section{Microzonation}

The wide spread in the peak acceleration data evident in Figure 2 will in large part be due to site effects such as resonance or broad-band amplification. Examples of both have already been noted in many of the fully processed accelerograms $[6,27,36]$.

Site resonance, ie strong amplification either at a single frequency or over a well defined narrow band of frequencies, is usually associated with the presence near surface of soft deposits such as recent marine or estuarine sediments, overlying distinctly firmer materials. Well known examples of resonance occur on the former lake bed zone of Mexico City [5] and in the bay mud regions of San Francisco [4], both of which have repeatedly and selectively suffered severe damage from large earthquakes. Locations in New Zealand that have shown signs of resonance include soft sediment sites at Wairoa, Gisborne, Hanmer Springs, Hutt City and Wellington. The evidence consists of the repeated occurrence of well defined peaks in Fourier spectra calculated from strong-motion records, and for Hutt City and Wellington it is supported by comparisons of matched records from rock, firm soil, and soft soil sites (Fig. 3). Amplification factors of up to 5 in the PGA are anticipated for input rock motions of small to moderate intensity $[27,36]$.

A distinctly different form of amplification has been observed at sites above deep soils. Instead of there being a dominant and repeated resonant peak in the Fourier spectrum of the acceleration, the amplification is generally spread over a period band that can be up to several seconds wide. Examples of such sites in New Zealand are located in Te Anau, Wanaka, Murchison, and Hutt City [11,27]. Their characteristic feature seems to be the presence of some hundreds of metres depths of sediments, which may include soft layers, but which do not have a distinct hard-soft boundary within a few tens of metres of the surface.

Strong-motion data from the Wellington region formed one of the inputs to recent assessments of ground shaking hazard in Wellington, Porirua, and the Hutt Valley, which were carried out for the Wellington Regional Council $[38,39]$. 


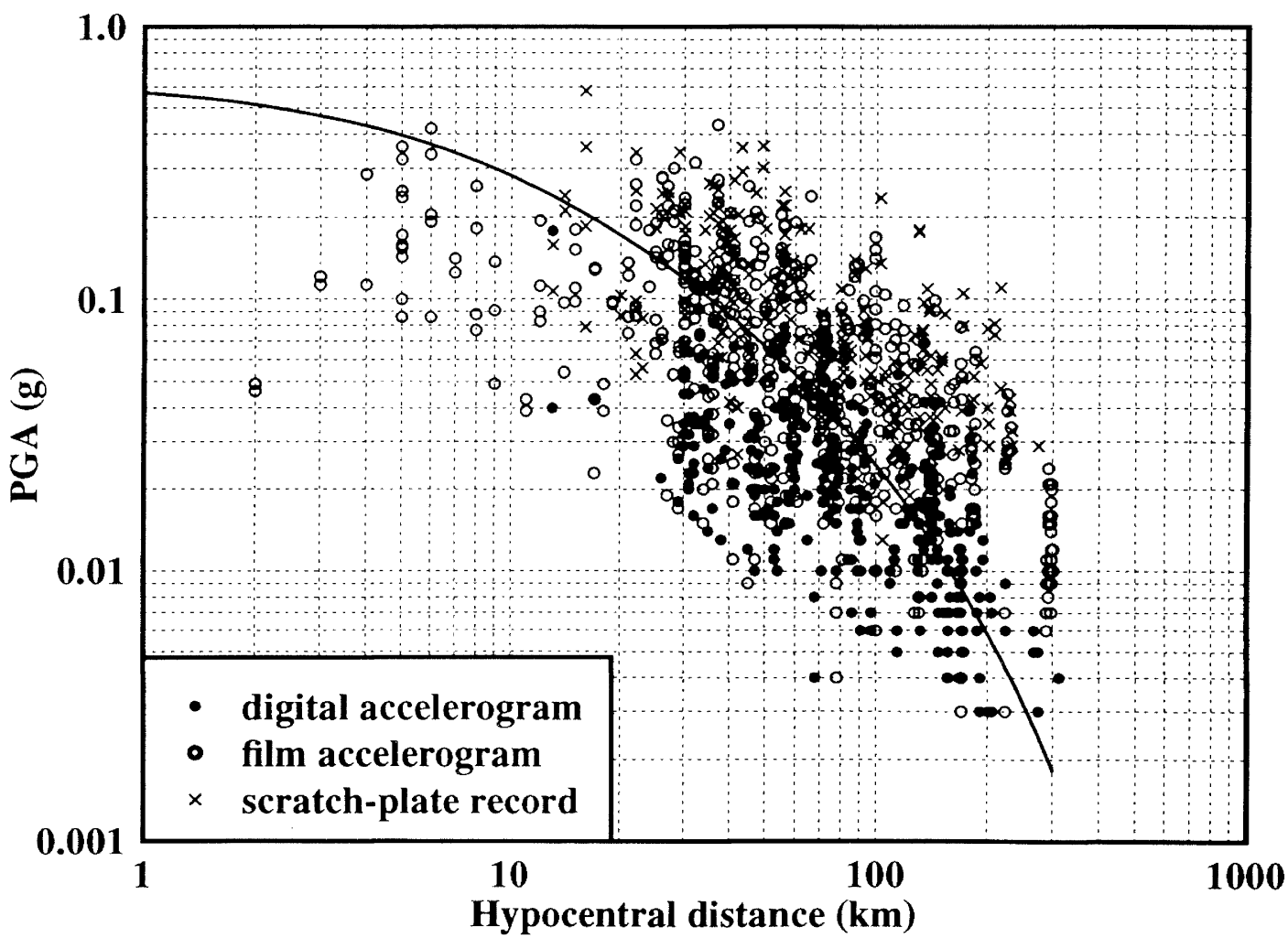

Figure 2. Orthogonal component PGA values derived from strong motion recordings made by the New Zealand network between 1965 and 1992 The reconded PGA values have been normalised to a magnitude of 60 using the Fukushima and Tanaka formula, and the solid line is the PGA predicted by the formula for an event of magnitude 6.0.

\section{Building response studies}

Many sets of records have been obtained from arrays in buildings since the first array was installed in the Vogel building in Wellington in 1969. Thirty-five of the sets are strong enough to be potentially useful for response analyses, ie, at least one peak acceleration in each set exceeds $0.05 \mathrm{~g}$. To date, the responses of the Vogel building and the Gisborne Post Office are the only ones that have been studied in any detail. McVerry [25] used a system identification technique to model the recorded responses of the Vogel building to two earthquakes, and recently Zhao [40] has demonstrated that soil-structure interaction effects are significant at the Vogel site. Zhao used two approaches to the modelling. He (a) developed and applied a simple analytical model of a single-mass structure on soft-soil springs and dashpots, and (b) applied a transfer function technique to the strong-motion records. He was able to identify both structural and soil-foundation parameters, including the fixed-base first-mode frequency, the base-translation and rocking frequencies, and the corresponding damping ratios.

Two ground accelerograms from the IGNS network, one obtained from the base of Matahina Dam during the 1987 Edgecumbe earthquake and one obtained from Dannevirke during the 1990 Weber earthquake of 13th May, have reached approximately code-level design strength. In both cases, the 5 damped acceleration response spectra were comparable in strength to the spectrum for the widely used El Centro 1940 SOOE component, and also to the design loadings code spectrum from the recently adopted New
Zealand code NZS 4203:1992. Structures were damaged near both sites and Matahina Dam itself [28] required extensive remedial work. However, the amount of damage in Dannevirke (population about 5800) was surprisingly light given the value of the PGA. Six brick buildings were sufficiently badly damaged to require demolition, and a further 12 required moderate repairs [15].

In an attempt to understand the low level of damage in Dannevirke, Sritharan and Dowrick [15,37] carried out dynamic analyses on four types of structure representative of those found in Dannevirke. The buildings were a pre-code single-storey unreinforced brick masonry building (UBM), a two-storey reinforced concrete block masonry building (RCBM), and a two-storey moment resisting frame building (MRF) both with and without infill panels. The work is still ongoing but some preliminary conclusions have been drawn. It was found that the UBM and RCBM buildings could be regarded as rigid structures for the loadings imposed, and in neither case were the forces calculated sufficient to yield the structures. The MRF building however showed highly non-linear response when a bare frame model was used, but it too was found to behave elastically when the infill panels in the frames were taken into account. Note that the accelerograph which recorded the Weber earthquake of 13th May was sited in the RCBM building.

Matahina dam records from the 1987 Edgecumbe earthquake

Matahina Dam, a large (350m long, $86 \mathrm{~m}$ high) earth and rockfill dam constructed in the mid-1960's, was within the 

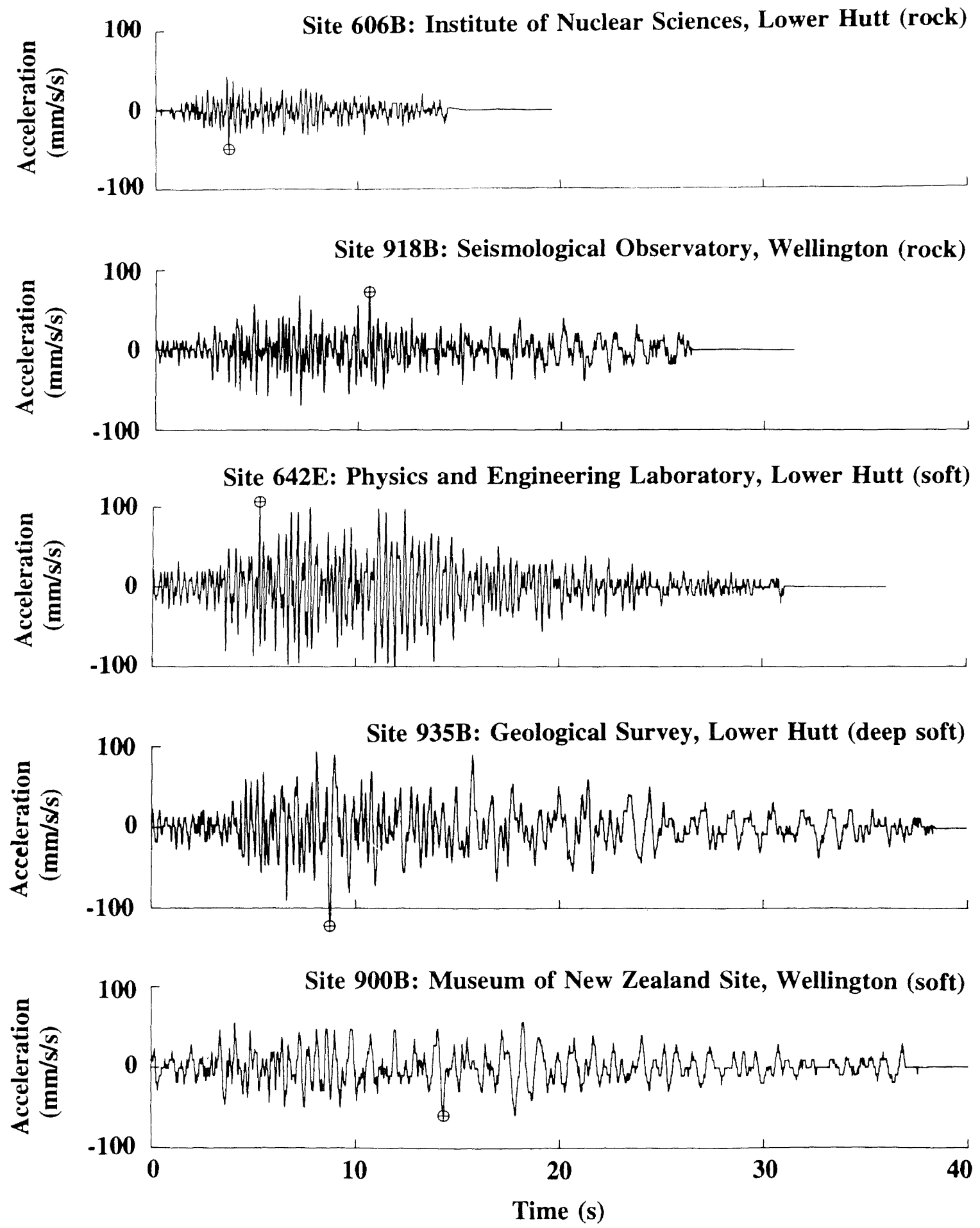

Figure 3. Strongest horizontal components from digital accelerograms recorded in Lower Hutt and Wellington during the Weber earthquake of 19th February 1990. The accelerograms are plotted on identical scales to highlight possible microzoning effects. 


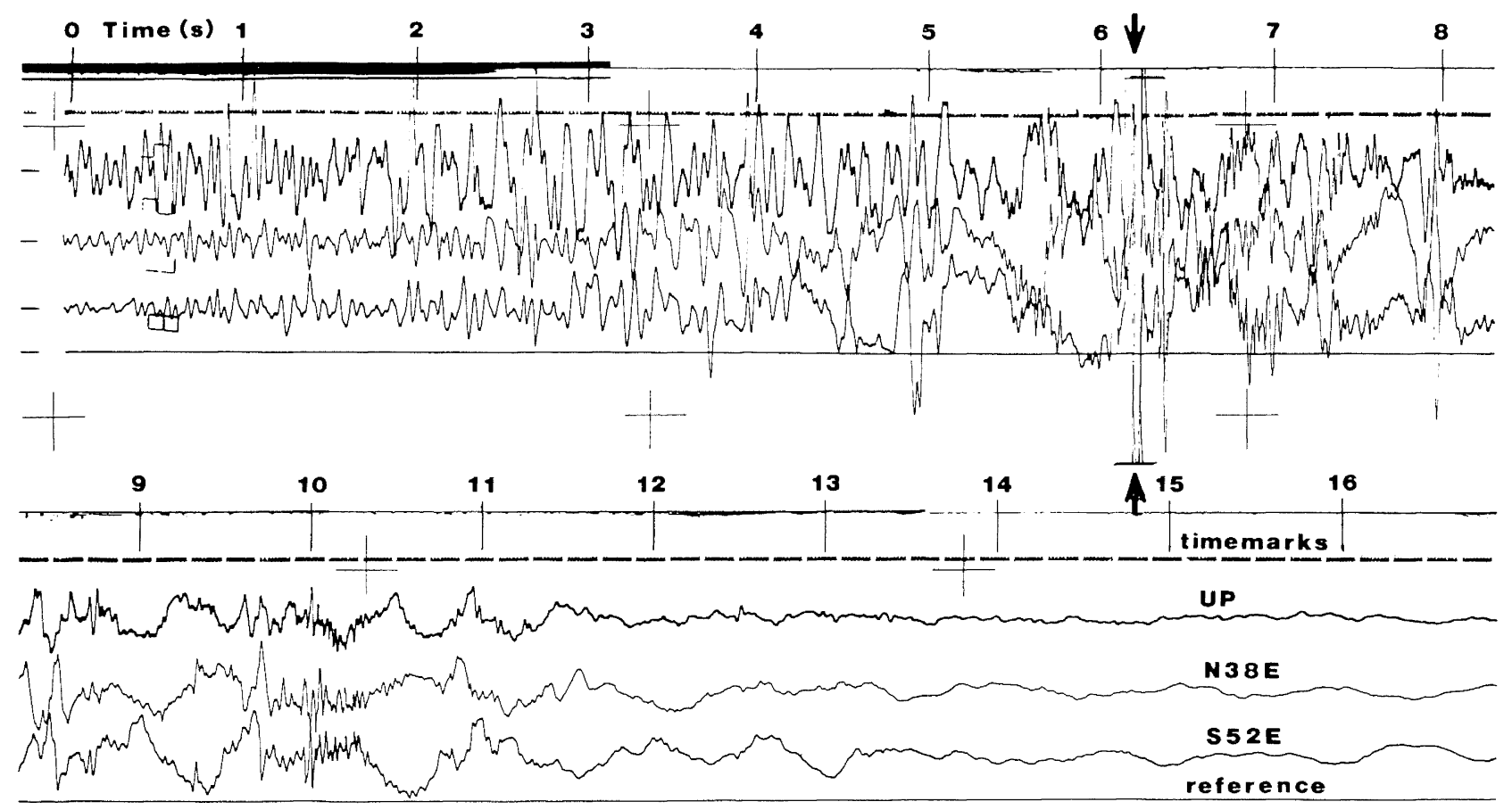

Figure 4. First 16 seconds of the Edgecumbe mainshock accelerogram from site 085E on Matahina dam. Note the discontinuity (arrowed) 6.14s from the start. All signal traces go off scale, there is a break in the timemark sequence, and the reference trace is thinned. The labeled orientations of the horizontal traces correspond to the sensing axes of the accelerometers which are at 45= to the nominal accelerograph axes.

MM8 isoseismal of the 1987 Edgecumbe earthquake. The ground input motions, and the response of the dam, were recorded on an array of 5 accelerographs located on the dam $[7,8]$. Although the peak ground acceleration was only moderately high at $0.33 \mathrm{~g}$, the dam responded strongly and the highest acceleration recorded on it was at least twice as high. At 6.14 seconds after the start of the response records, all three signal traces of the right crest site went off scale (Fig. 4). This implies accelerations above $1.0 \mathrm{~g}$, due either to the response of the dam or to impacts on the accelerograph's protective enclosure. Certainly many of the rockfill boulders on the surface of the dam moved during the earthquake, and after the earthquake the enclosure was found to have been gouged by falling boulders [8].

Studies of the response of Matahina dam based on the Edgecumbe records have raised questions about the validity of commonly used distributions of shear modulus and yield stress used in the dynamic modelling of earth dams [28]. The uppermost third of Matahina dam responded in a strongly nonlinear fashion during the strongest few seconds of the earthquake.

\section{The Weber earthquakes of 19th February 1990 and 13th May 1990}

Excellent sets of records were obtained from the Weber earthquakes of 19th February 1990 and 13th May $1990[9,10]$. Included amongst them was New Zealand's highest peak ground acceleration recorded on an accelerograph, $0.40 \mathrm{~g}$ from Dannevirke (Fig. 5), and sets of records from hard and soft sites in the Hutt Valley and Wellington that have demonstrated microzonation effects (Fig. 3) [36].

Nearly all of the Wellington and Hutt Valley records were from digital accelerographs. At epicentral distances of 150 to $180 \mathrm{~km}$ the shaking was too small to trigger many of the film-recording accelerographs, and those film records that were obtained were incomplete and too small to be processed satisfactorily.

Another feature of the records that is worthy of further study is the striking difference between the two records obtained from Dannevirke. Thr record from the 13th May earthquake contained much more high frequency ( 5 to $25 \mathrm{~Hz}$ ) signal than the record from the 19th February earthquake (Fig. 6), particularly in the vertical component, which may reflect differences between the mechanisms of the two events. The first event occurred within the the upper part of the subducting Pacific plate on a normal fault, while the second event was located within the overlying Australian plate and involved thrusting and strike-slip motion [33].

\section{The Hawks Crag earthquakes of January and February 1991.}

Three earthquakes with magnitudes close to 6 occurred near Westport on the 28th January and 15th February 1991 [11]. Two of the events were located near a prominent geographical feature known as Hawks Crag, and were within $10 \mathrm{~km}$ of an accelerograph located on a rock site at Te Kuha 


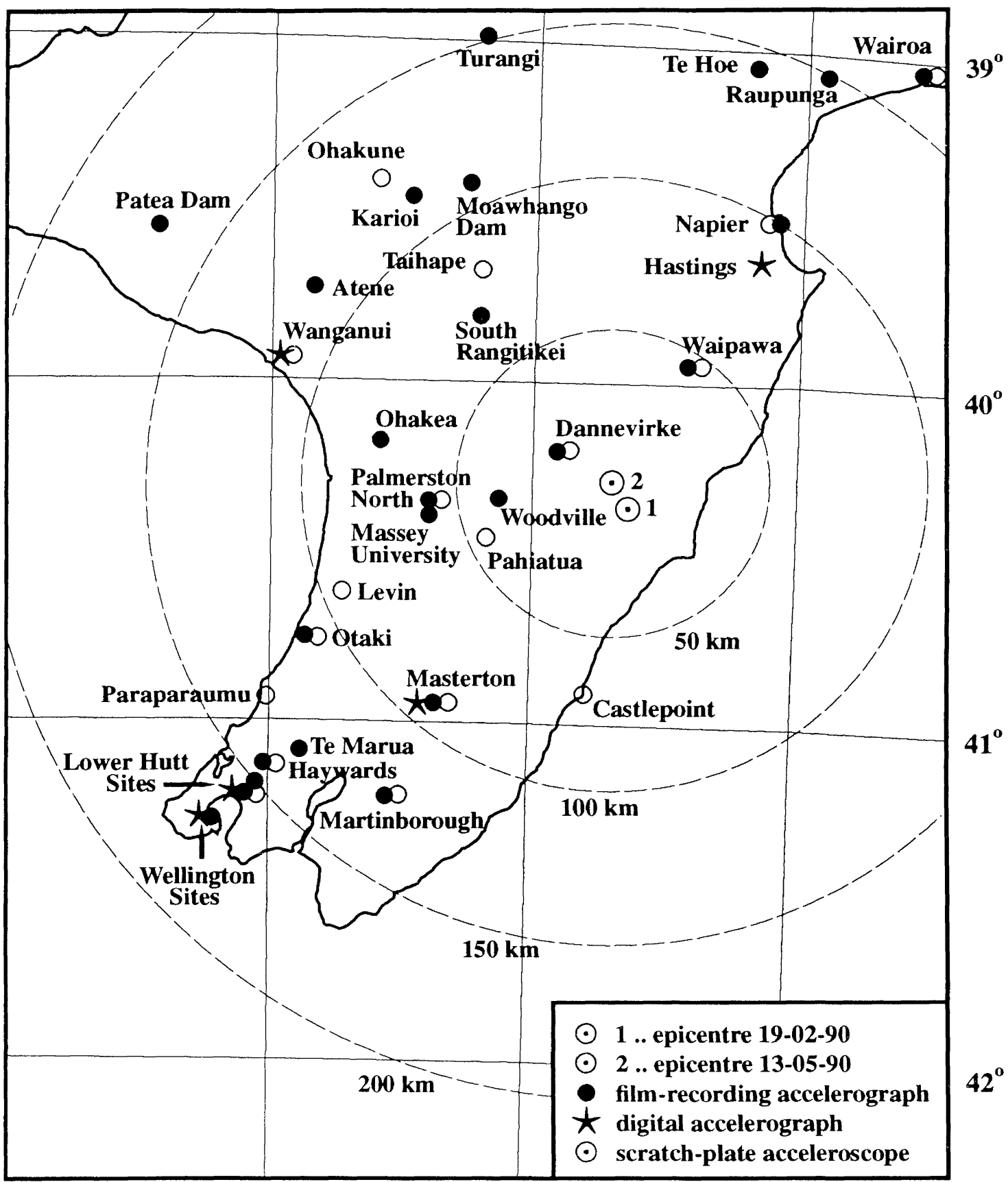

Figure 5. Strong-motion recording sites within $200 \mathrm{~km}$ of the epicentre of the Weber earthquakes of 19 th February 1990 and 13 th May 1990.

(Fig. 7). Peak ground accelerations of 0.21 and $0.14 \mathrm{~g}$ were obtained. The strongest record of the sequence, $0.3 \mathrm{~g}$, was obtained from a deep alluvial site at Murchison at an epicentral distance of $54 \mathrm{~km}$. Some very small records were obtained from digital accelerographs in Wellington and the Hutt Valley at epicentral distances of about $180 \mathrm{~km}$, and while much too small to be of engineering interest provided input to attenuation studies.

\section{THE FUTURE}

New Zealand's data base for modelling earthquakes ground motions and hazard is growing to a point where reliable locally-based models are feasible, though data and models from overseas will continue to be important until data becomes available from a number of sites with a range of ground conditions and from a range of structures, from truly large New Zealand earthquakes. In particular the network has not yet yielded any time-history data from the highest 


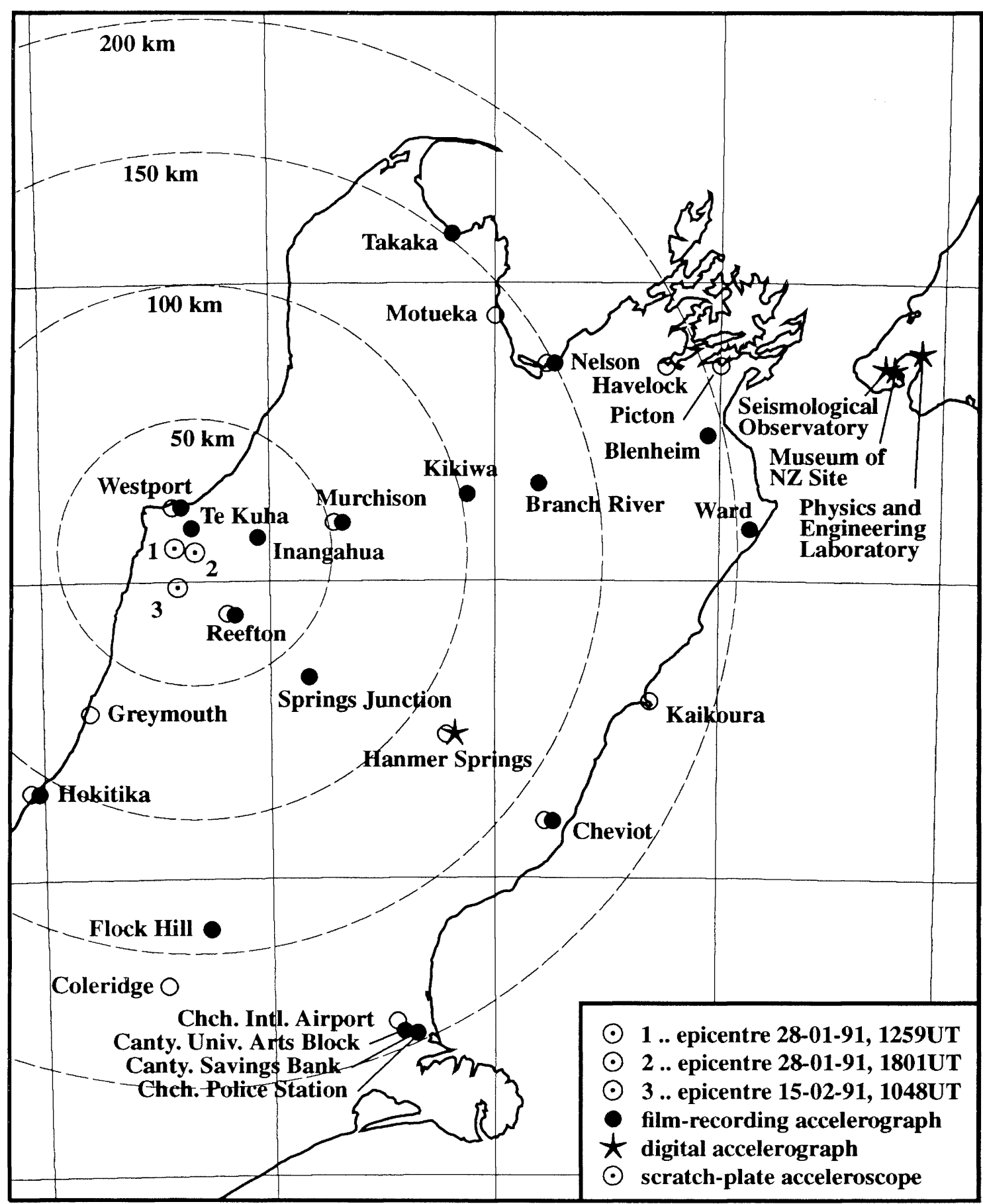

Figure 6. Comparison of the first 8 seconds from each of the accelerograms recorded at Dannevirke during the Weber earthquakes of 19 th February 1990 and 13th May 1990. Each sample contains three signal traces, a reference trace, superimposed

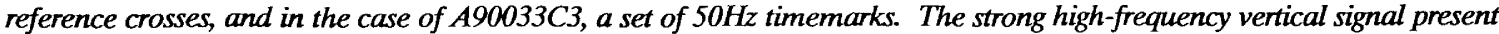
in the early part of $A 90033 C 3$ is clear. The first event was located within the upper part of the subducting Pacific plate, on a normal fault, and the mechanism is thought to reflect down-dip tension within the subducting plate. The second event occurred on an imbricate fault in the overtying Australian plate, and involved both thrusting and strike-slip motion [33]. 


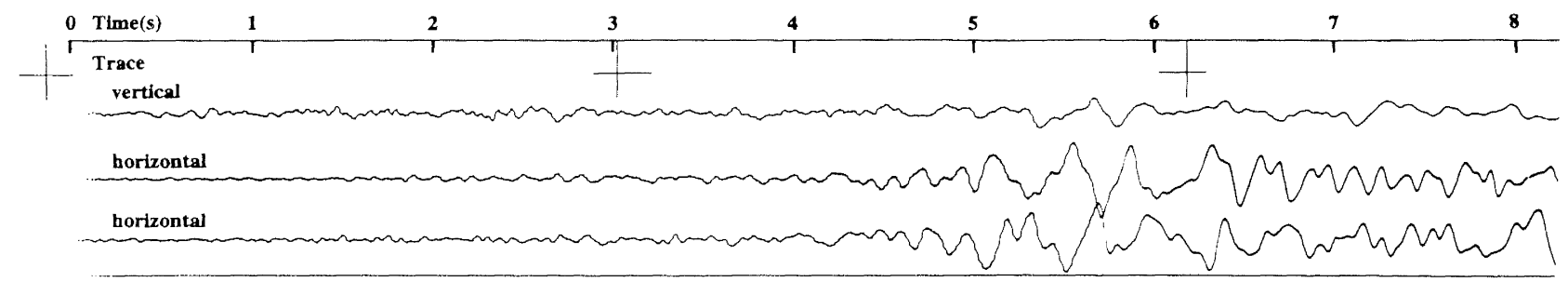

Record A90033A1, Dannevirke Telephone Exchange, 19th February 1990
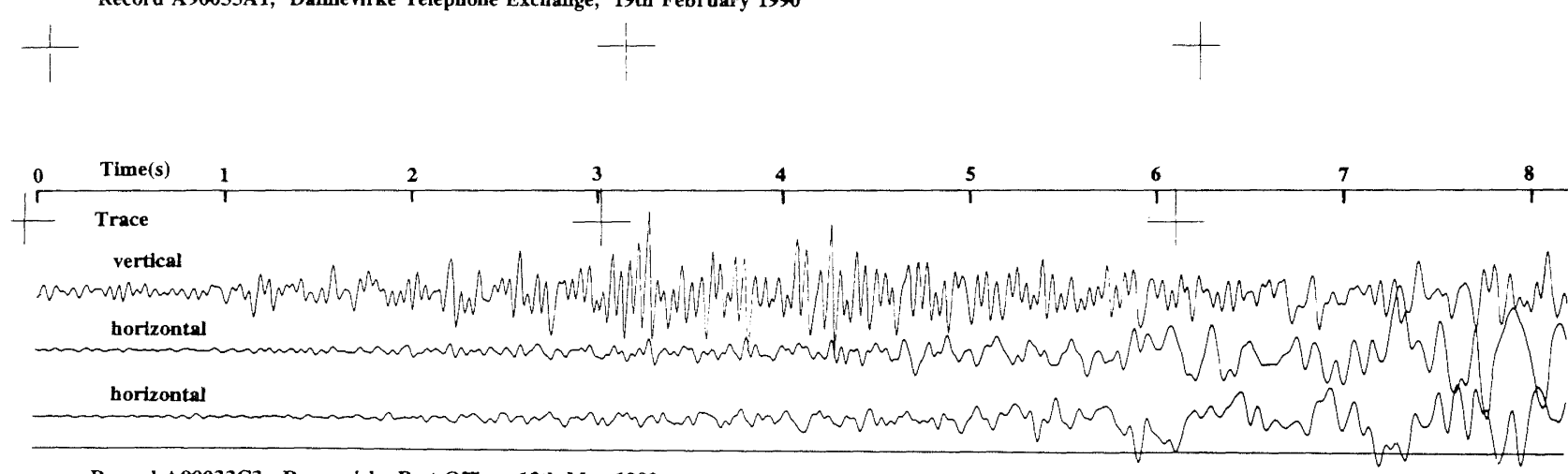

Record A90033C3, Dannevirke Post Office, 13th May 1990
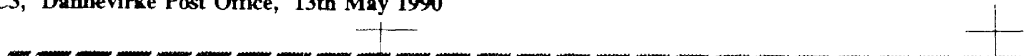

Figure 7. IGNS strong-motion recording sites close to the epicentres of three earthquakes (Hawks Crag) near Westport in 1991. The dashed circles show distances from event 2

intensity (MM9 or MM10) zones of a major New Zealand earthquake. The three strongest time-history records from ground sites in the data base were obtained from the MM8 and MM7 zones of the 1987 Edgecumbe and 1990 Weber earthquakes, and while useful for design and research purposes do not represent the strength of motions to be expected from, for example, a magnitude 7.5 earthquake on the Wellington fault.

Plans for the strong-motion recorder network include a systematic upgrading that will involve the gradual replacement of existing, obsolete analogue accelerographs with digital models, and the installation of accelerographs at 2 new sites each year for several years. The upgrade will include instrumenting near-fault locations and new ground sites of interest for microzoning studies. Priority will also be given to installation of sets of accelerographs in new buildings reflecting latest design and construction practices, as most of the currently instrumented buildings were constructed in the 1970s.

A major long term-goal is to create attenuation models which make proper allowance for variations in ground conditions. Collecting an appropriate database on ground conditions at the accelerograph is essential to this task. Analysis of the available data and incorporation into our attenuation models is proposed, with upgrades from time to time as more data (ground conditions and ground motions) become available.

The treatment of uncertainties in data, parameter values and prior model specification in seismic hazard and risk modelling is often incomplete and inadequate. For example, uncertainties in basic data such as magnitude and hypocentral determinations and measurements of strength of shaking are often ignored. Indeed the models currently used for describing seismicity and attenuation of ground shaking make no allowance for data uncertainties. Parameter uncertainties are sometimes taken into account (as in most attenuation models) and sometimes ignored (as in most seismicity models). At least one key parameter, maximum magnitude, is most often estimated informally and subjectively. Improvement of the treatment of uncertainties in data and parameters and improved understanding of the sensitivity of the estimates to model selection is a key element in improving estimation of seismic hazard. This is particularly important in the near-source region where experimental data is sparse and the hazard is greatest. This is a big task which we plan to tackle methodically over several years as improvements are made to the data bases and models.

Current risk assessment procedures rely heavily on damage ratios, which relate the cost of seismic damage to the intensity of shaking. Until recently the damage ratios have been poorly evaluated. This unsatisfactory situation was partly resolved by the derivation of damage ratios appropriate to the MM6 to MM9 zones of an earthquake using insurance-industry claims records from the 1987 Edgecumbe earthquake $[13,14]$, but the very important damage ratios for MM10 still had to be estimated by extrapolation. However we are now in a position to derive the MM10 damage ratios following the discovery of a major set of claims data giving the costs of damage to individual houses in Napier due to the 1931 Napier earthquake. This valuable find will help the establishment of damage ratios for $\mathrm{NZ}$ houses of pre 1931 vintage, and conservative damage ratios for modern construction. The data will also highly valuable in microzonation studies, and an early task will be the comparison of variations in observed damage with those predicted by topographic and site response models. The opportunity to undertake this comparison is nearly unique 
worldwide.

Studies of structural responses and damage in a series of past earthquakes are planned. This includes an extension of current modelling of building responses to the strong-motion accelerogram from the Weber earthquake of May 1990. One of the problem areas is that procedures for analysing structures in which in-fill walls contribute to overall seismic-resistance are most unsatisfactory. An improved procedure for modelling such "non-structural" elements will be developed.

Further development of nonlinear analysis procedures is proposed. Two topics of special interest are (a) system identification for nonlinear systems, with application to the response of Matahina dam, and (b) the use of system identification and modal analysis techniques in situations where soil-structure interactions are significant, with application to the Vogel building and the Gisborne Post Office. Of particular interest, an excellent set of records was retrieved from the Gisborne Post Office following the recent (10 August 1993) magnitude 6.4 earthquake centred about $15 \mathrm{~km}$ to the north of Gisborne. The peak accelerations recorded at the ground and top floor sites were $0.2 \mathrm{~g}$ and $0.4 \mathrm{~g}$ respectively, which are the largest recorded to date by any building array of accelerographs in the New Zealand network.

To conclude, the outlook is good for the continuation of strong-motion recording in New Zealand and the seismic hazard and structural research based on the strong-motion data. Crown funding for the IGNS work is reviewed at 1 to 3 yearly intervals and to date the work has received strong support from the Foundation for Research, Science and Technology (FRST, the Crown funding agency) and its referees.

\section{ACKNOWLEDGEMENTS}

The staff of Engineering Seismology Section gratefully acknowledge support from many organisations and individuals in the maintenance of the New Zealand strong-motion network. We wish in particular to thank the Crown and its agencies who provide the bulk of our funding, the Earthquake and War Damage Commission who have funded the majority of the digital accelerographs in the network, the former Ministry of Works and Development who have arranged funding for many film-recording accelerographs in buildings, Electricorp, Shell Todd Oil Services, the Wellington Regional Council, and the Road Research Unit of Transit New Zealand who for many years have funded the servicing of accelerographs in structures of special interest, and finally those many organisations and individuals who house our instruments.

\section{REFERENCES}

1. Baguley, D.E., 1993, "Report of calibration of a DCA-333R digital accelerograph", Science Report No. $93 / 29$, Institute of Geological and Nuclear Sciences, Lower Hutt.

2. Beck, J.L., Randal, P.M., Hefford, R.T., 1981, "Computer analyses of New Zealand earthquake accelerograms, Volume 1", Physics and Engineering Laboratory DSIR, Lower Hutt, New Zealand.
3. Berrill, J.B., 1979, "Suggested extensions of the New Zealand strong-motion accelerograph network", Bulletin of the New Zealand National Society for Earthquake Engineering 12(3):264-268.

4. Borcherdt, R.D., 1991, "On the observation, characterization, and predictive GIS mapping of strong-ground motion for seismic zonation", Proceedings of the Pacific Conference on Earthquake Engineering, New Zealand, 20-23 November 1991, Vol. 1:1-24.

5. Butcher, G., Hopkins, D., Jury, R., Massey, W., McKay, G., McVerry, G., 1988, "The September 1985 Mexico earthquakes: final report of the New Zealand reconnaissance team", Bulletin of the New Zealand National Society for Earthquake Engineerıng, 21(1):3-96.

6. Cousins, W.J., Hefford, R.T., McVerry, G.H., Downer, R.M., 1986, "Computer analyses of New Zealand earthquake accelerograms, Volume 2, 1981-1985", Physics and Engineering Laboratory DSIR, Lower Hutt, New Zealand.

7. Cousins, W.J., Hefford, R.T., McVerry, G.H., O'Kane, S.M., 1988, "Computer analyses of New Zealand earthquake accelerograms, Volume 3, Ground records from from the 1987 Edgecumbe Earthquake", Physics and Engineering Laboratory, DSIR, Lower Hutt, New Zealand.

8. Cousins, W.J., Hefford, R.T., McVerry, G.H., O'Kane, S.M., 1988, "Computer analyses of New Zealand earthquake accelerograms, Volume 4, Matahina Dam records from the 1987 Edgecumbe Earthquake", Physics and Engineering Laboratory, DSIR, Lower Hutt, New Zealand.

9. Cousins, W.J., Hefford, R.T., McVerry, G.H., Baguley, D.E., O'Kane, S.M., 1991, "Computer analyses of New Zealand earthquake accelerograms, Volume 5, The Weber earthquake of 19th February 1990", DSIR Physical Sciences, Lower Hutt, New Zealand.

10. Cousins, W.J., Hefford, R.T., McVerry, G.H., O'Kane, S.M., Baguley, D.E., 1991, "Computer analyses of New Zealand earthquake accelerograms, Volume 6, The Weber earthquake of 13th May 1990", DSIR Physical Sciences, Lower Hutt, New Zealand.

11. Cousins, W.J., Hefford, R.T., McVerry, G.H., O'Kane, S.M., Baguley, D.E., 1991, "Computer analyses of New Zealand earthquake accelerograms, Volume 7, Three earthquakes near Westport in January and February 1991", DSIR Physical Sciences, Lower Hutt, New Zealand.

12. Cousins, W.J., Porritt, T.E., Hefford, R.T., O'Kane, S.M., Baguley, D.E., McVerry, G.H., 1993, "Peak accelerations from New Zealand earthquake accelerograms", Science Report, Institute of Geological and Nuclear Sciences, Lower Hutt.

13. Dowrick, D.J., 1991, "Damage costs for houses and farms as a function of intensity in the 1987 Edgecumbe earthquake", Earthquake Engineering and Structural Dynamics, 20:455-469. 
14. Dowrick, D.J., Rhoades, D.A., "Damage costs for commercial and industrial property as a function of intensity in the 1987 Edgecumbe earthquake", Earthquake Engineering and Structural Dynamics. (In press).

15. Dowrick, D.J., Sritharan, S., 1993, "Response of low-rise buildings to the May 1990 Weber earthquake", New Zealand National Society for Earthquake Engineering, Technical Conference and AGM, Wairakei, March 26-28, Proceedings:112-118.

16. Dowrick, D.J., Sritharan, S., 1993, "Attenuation of peak ground acceleration in some recent New Zealand earthquakes", Bulletin of the New Zealand National Society for Earthquake Engineering 26(1):3-13.

17. Dowrick, D.J., Sritharan, S., "Peak ground accelerations recorded in the 1968 Inangahua earthquake, and some attenuation implications", submitted to Bulletin of the New Zealand National Society for Earthquake Engineering, Feb. 1993.

18. Fukushima, Y., Tanaka, T., 1990, "A new attenuation relation for peak horizontal acceleration of strong earthquake ground motion in Japan", Bulletin of the Seismological Society of America, 80:757-783.

19. Hefford, R.T., Randal, P.M., 1983, "Procedures for operating the New Zealand strong-motion accelerograph network", Bulletin of the New Zealand National Society for Earthquake Engineering, 16(1): 45-58.

20. Hefford, R.T., Randal, P.M., Skinner, R.I., Beck, J.L., Tyler, R.C., 1979, "The New Zealand strong motion earthquake recorder network", Bulletin of the New Zealand National Society for Earthquake Engineering, 12(3): 256-263.

21. Hodder, S.B., Skinner, R.I., Hefford, R.T., Randal, P.M., 1978, "Strong-motion records of the Milford Sound earthquake 1976 May 4", Bulletin of the New Zealand National Society for Earthquake Engineering, 11(3):184-190.

22. Hefford, R.T., Tyler, R.G., Skinner, R.I., 1980, "The MO2A strong-motion accelerograph", Bulletin of the New Zealand National Society for Earthquake Engineering, 13(4):374-379.

23. Hodder, S.B., 1983, "Computer processing of New Zealand strong-motion accelerograms", Bulletin of the New Zealand National Society for Earthquake Engineering, 16(3): 234-246.

24. Matuschka, T., Davis, B.K., 1991, "Derivation of an attenuation model in terms of spectral acceleration for New Zealand", Proceedings of the Pacific Conference on Earthquake Engineering, New Zealand, 20-23 November 1991, Vol. 2:123-134

25. McVerry, G.H., 1984, "Comparison of remote site and basement records as excitation of the Vogel building", Bulletin of the New Zealand National Society for Earthquake Engineering, 17:3-14.
26. McVerry, G.H., 1986, "Uncertainties in attenuation relations for New Zealand seismic hazard analysis", Bulletin of the New Zealand National Society for Earthquake Engineering, 19(1): 28-39.

27. McVerry, G.H., Sritharan, S., 1991, "Earthquake site response effects demonstrated by New Zealand strong-motion records", Proceedings of the Pacific Conference on Earthquake Engineering, New Zealand, 20-23 November 1991, Vol. 3:205-216.

28. McVerry, G.H., Zhao, J.X., 1992, "Nonlinear modelling of the recorded response of Matahina dam", Proceedings of the 10th World Conference on Earthquake Engineering 8:4683-4688.

29. Mulholland, W.M. (1984) "Estimation of design earthquake motions for New Zealand". Research Report 82-9, Dept of Civil Engineering, University of Canterbury.

30. Porritt, T.E., Baguley, D.E., 1993, "Report of calibration of an acceleroscope", Science Report No. 93/30, Institute of Geological and Nuclear Sciences, Lower Hutt.

31. Reyners, M.E., Hodder, S.B., 1985, "The Motu river earthquake of 8 March 1984", Bulletin of the New Zealand National Society for Earthquake Engineering, $18(1): 41-54$.

32. Reyners, M.E., Gledhill, K.R., Waters, D., 1991, "Tearing of the subducted Australian plate during the Te Anau, New Zealand, earthquake of 1988 June 3", Geophysical Journal International, 104:105-115.

33. Robinson, R., "Shallow subduction tectonics and fault interaction: the Weber, New Zealand, earthquake sequence of 1990-1992", Journal of Geophysical Research (In press).

34. Skinner, R.I., Stephenson, W.R., 1973, "Accelerograph calibration and accelerogram correction", Earthquake Engineering and Structural Dynamics 2(1):71-86.

35. Smith, W.D., 1976, "A computer file of New Zealand earthquakes", Bulletin of the New Zealand National Society for Earthquake Engineering, 9(2):136-137.

36. Sritharan S, McVerry G H, "Microzone effects in the Hutt Valley in Records from a strong-motion accelerograph array", Bulletin of the New Zealand National Society for Earthquake Engineering 25(4):246-264 (1992)

37. Sritharan, S., Dowrick, D.J., "Response of low-rise buildings to moderate ground shaking, particularly the May 1990 Weber earthquake", submitted to the Bulletin of the New Zealand National Society for Earthquake Engineering.

38. Van Dissen, R.J., Taber, J.J., Stephenson, W.R., Sritharan, S, Read, S.A.L., McVerry, G.H., Dellow, G.D. Barker, P.R., 1992, "Earthquake ground shaking hazard assessment for the Lower Hutt and Porirua areas, New Zealand", Bulletin of the New Zealand National Society for Earthquake Engineering 25(4):286-302. 
39. Van Dissen, R.J., Taber, J.J., Stephenson, W.R., Sritharan, S, Perrin, N.D., McVerry, G.H., Campbell, H.J., Barker, P.R., 1993, "Ground shaking hazard zonation for Wellington City and suburbs, New Zealand", New Zealand National Society for Earthquake Engineering, Technical Conference and AGM, Wairakei, March 26-28, Proceedings:134-141.

40. Zhao, J.X., 1993, "Identification of soil-structure system parameters from earthquake records using an analytical model", papers in preparation.

41. "A preliminary report on the Inangahua earthquake, New Zealand, May 24, 1968", Bulletin of the New Zealand National Society for Earthquake Engineering 2(1):1-148 (1969).

42. Special Issue - The 1987 Edgecumbe earthquake, New Zealand Journal of Geology and Geophysics, 32(1)1-190 (1989). 